\title{
Fabrication and Super-Antibacterial Property of Nanosilver/Sericin/Poly(ethylene oxide) Nanofibers through Electrospinning-Combined Postdeposition Method
}

\author{
Jia Li, ${ }^{1,2}$ Bo-Xiang Wang, ${ }^{1,2}$ Yi-Fan Cui, ${ }^{2}$ Zhi-Cai Yu, ${ }^{1,2}$ Xu Hao, ${ }^{1,2}$ \\ Feng-Yuan Huang, ${ }^{1,2}$ De-Hong Cheng, ${ }^{1,2}$ and Yan-Hua Lu ${ }^{1,2}$ \\ ${ }^{1}$ Liaoning Provincial Key Laboratory of Functional Textile Materials, Eastern Liaoning University, Dandong, Liaoning 118000, China \\ ${ }^{2}$ School of Chemical Engineering, Eastern Liaoning University, Dandong, Liaoning 118003, China \\ Correspondence should be addressed to De-Hong Cheng; chengdehongldxy@qq.com and Yan-Hua Lu; yanhualu@aliyun.com
}

Received 3 August 2016; Accepted 20 October 2016

Academic Editor: Mayakrishnan Gopiraman

Copyright ( $) 2016$ Jia Li et al. This is an open access article distributed under the Creative Commons Attribution License, which permits unrestricted use, distribution, and reproduction in any medium, provided the original work is properly cited.

Nanosilver particle has been used in the nanofiber mats by mixing the nanosilver with the spinning solution for improving the antibacterial property. Although studies have shown that the antibacterial property of nanofiber mats gets increasing, the higher silver content and the larger released resistance of nanosilver from nanofiber mats are obvious. Here, the electrospinning-combined postdeposition method was used to prepare the nanosilver/sericin/poly(ethylene oxide) (Ag/SS/PEO) nanofiber mats and the bacterial reduction rates against Staphylococcus aureus (S. aureus) and Escherichia coli (E. coli) were analyzed. We found that the $\mathrm{Ag} / \mathrm{SS} / \mathrm{PEO}$ nanofiber mats were excellent antibacterial properties at the lower silver content and the bacterial reduction rates against $S$. aureus and E. coli all reached above $99.99 \%$. Our data suggests that the antibacterial property can be improved by introducing the electrospinning-combined postdeposition method.

\section{Introduction}

Nanosilver with the lower toxicity and the longer antibiotics time is a typical nanoantibiotic material in antibacterial agents $[1,2]$. At present, there is no efficient usage of nanosilver for nanofiber mats, especially for sericin nanofiber mats. Mixing the nanosilver with the polymer solution prior to electrospinning is a general technique for nanofiber mats, as many studies have demonstrated favorable results in various nanofiber mats [3-6].

Sericin (SS) has been used in a variety of biomedical applications such as wound dressing and tissue engineering, due to the larger hygroscopicity, biocompatibility, biodegradability, and other properties [7, 8]. Several early phase studies involving sericin nanofiber mats with nanosilver are now underway with promising outcomes [9]. However, the resulting nanofiber mats by the general techniques still have some problems as biomedical materials. Among the major hurdles for biological application, it needs enough higher silver content in order to achieve strong antibacterial properties. The literature has reported that the smaller Ag $(20 \mathrm{~nm})$, regardless of coating, are toxic in cell types [10]. The more the nanosilver, the more toxic the resulting products. An additional concern with this polymer for improving sericin nanofiber forming property is that it has good biodegradability, biocompatibility, and spinnability. It has been proved that the nanofiber forming property can be greatly improved by adding PEO [11-13]. This literature has reported that the keratin spinnability by adding the PEO is improved [14].

In this study, we aim to explore whether electrospinningcombined postdeposition method is able to fabricate the nanosilver/sericin/poly(ethylene oxide) nanofiber mats and whether the new approach can improve the antibacterial property and obtain the super-antibacterial property nanofiber mats at the lower silver content. 


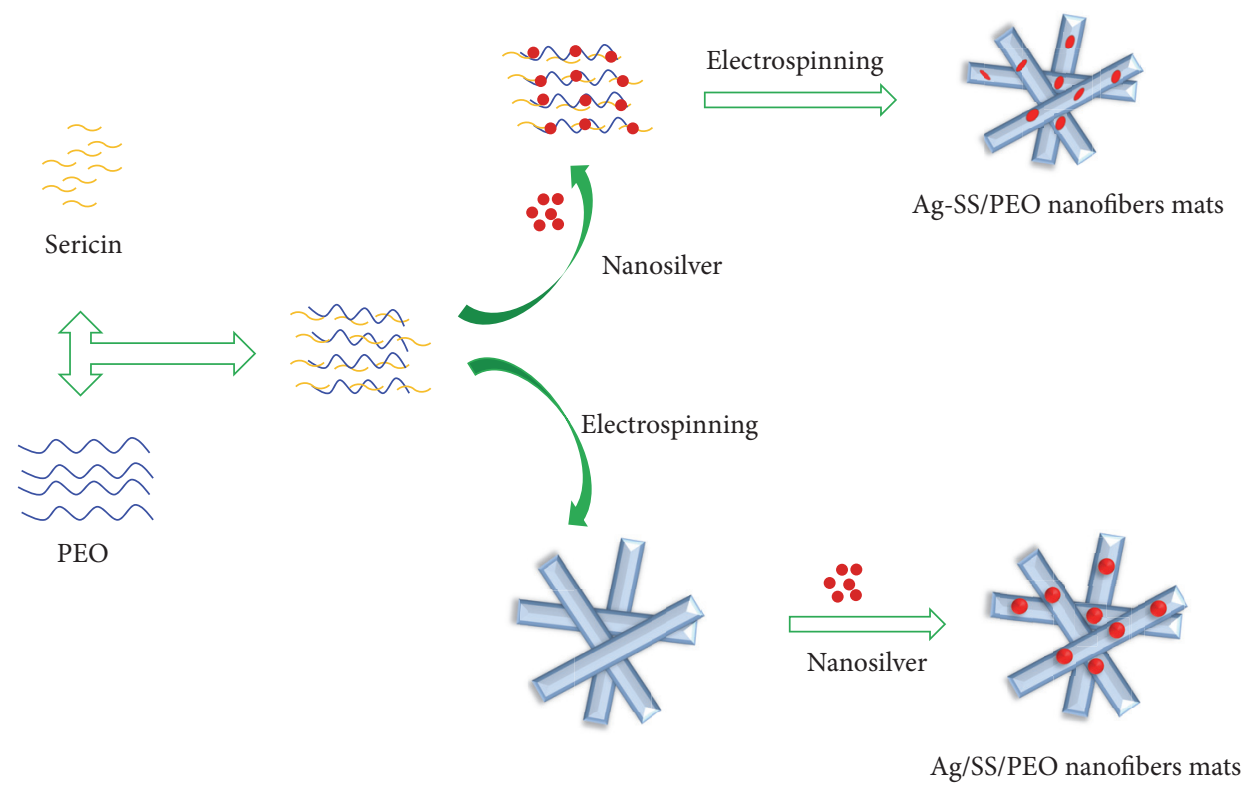

FIGURE 1: Scheme process of prepared nanofiber mats with nanosilver.

\section{Experiment and Methods}

2.1. Materials. Sericin $\left(M_{v}=90 \mathrm{kDa}\right.$, Shanghai, China) and poly(ethylene oxide) (PEO, $M_{v}=60 \mathrm{kDa}$, Shanghai, China) were used without further purification. Sodium hydroxide and sodium hypophosphite monohydrate were purchased from Tianjin Heng Xing Chemical Reagent Co., Ltd. (Tianjin, China). Citric acid and silver nitrate (kept away from light) were purchased from Sinopharm Chemical Reagent Co., Ltd. (Shanghai, China). S. aureus (ATCC 6538) and E. coli (ATCC 8099) were offered from Center for Disease Control and Prevention of Zhangjiagang (Jiangsu, China).

2.2. Preparation of Nanofiber Mats. In order to research the influence of nanosilver location for nanosilver effective utilization based on nanofiber mats, the nanosilversericin/poly(ethylene oxide) (Ag-SS/PEO) nanofiber mats and the nanosilver/sericin/poly(ethylene oxide) (Ag/SS/ PEO) nanofiber mats were separately prepared by precursor silver-loaded and electrospinning-combined postdeposition method.

The precursor silver-loaded meant that Ag-SS solution was obtained by adding dropwise silver nitrate ethanol solution into sericin solution with vigorously stirring at $60^{\circ} \mathrm{C}$ for $1 \mathrm{~h}$ firstly. And then the Ag-SS solution was blended with the prepared PEO solution with stirring at room temperature. The resulting Ag-SS/PEO solutions, whose ratio was maintained at 70/30 (v/v), were electrospun to obtain Ag-SS/PEO nanofiber mats. The electrospinning-combined postdeposition method referred to the prepared Ag/SS/PEO nanofiber mats that were developed by SS/PEO nanofiber mats being electrospun SS/PEO solutions and then immersed in silver nitrate ethanol solution kept away from light at room temperature for $15 \mathrm{~min}$. The process parameters of electrospinning were as follows: $30 \mathrm{kV}$ (voltage), $15 \mathrm{~cm}$ (distance between tip and receptor), $1.0 \mathrm{~mm} / \mathrm{s}$ (feed rate of the syringe pump), $60 \%$ (humidity), and $25^{\circ} \mathrm{C}$ (temperature).

The specific scheme and preparation process parameters of the Ag-SS/PEO nanofiber mats and the Ag/SS/PEO nanofiber mats were shown in Figure 1 and Table 1, separately.

2.3. Characterization. The morphologies of the Ag/SS/PEO nanofiber mats and Ag-SS/PEO nanofiber mats were analyzed using a scanning electron microscope (SEM, TM-1000, Hitachi, Japan). The properties of the secondary structure and degree of crystallinity of sericin were characterized by Fourier transform infrared spectroscopy (FT-IR, Tensor-37, Bruker, Germany) and X-ray diffraction (XRD, D8-Gadds, Bruker Axs, United States). The X-ray photoelectron spectroscopy (XPS, K-alpha, ThermoFisher, United States) and the Zetasizer Nano ZS particle size analyzer (ZEN 3500, Malvern, United Kingdom) were used to assess the characterization of the nanosilver particle size.

2.4. Antibacterial Testing. The antimicrobial activity of the nanofiber mats was tested against $S$. aureus and $E$. coli by using a shake-flask method according to the literature. The nanofiber mats $(0.75 \pm 0.07 \mathrm{~g})$, being cut into small pieces with size of around $0.5 \times 0.5 \mathrm{~cm}^{2}$, were placed separately in the bacterial suspension of $S$. aureus and E. coli. and then dipped into a flask containing $70 \mathrm{~mL}$ of $0.3 \mathrm{mM}$ phosphatebuffered saline (PBS, monopotassium phosphate, $\mathrm{pH} \approx 7.2$ ) culture solution with cell concentration of $1 \times 10^{5}-4 \times 10^{5}$ colony-forming units $(\mathrm{cfu}) / \mathrm{mL}$. The flask was then shaken at $150 \mathrm{rpm}$ on a rotary shaker at $24^{\circ} \mathrm{C}$ for $1 \mathrm{~h}$. From each incubated sample, $0.5 \mathrm{~mL}$ of culture solution before and after being shaken $1 \mathrm{~h}$ was taken, diluted, and distributed onto an agar plate. All plates were incubated at $37^{\circ} \mathrm{C}$ for $24 \mathrm{~h}$, and the 
TABLE 1: Preparation process parameters of nanofiber mats.

\begin{tabular}{|c|c|c|c|c|c|c|}
\hline & $\mathrm{SS} / \mathrm{mL}$ & $\mathrm{PEO} / \mathrm{mL}$ & Citric acid/g & $\mathrm{NaH}_{2} \mathrm{PO}_{2} \cdot \mathrm{H}_{2} \mathrm{O} / \mathrm{g}$ & $\mathrm{NaOH} / \mathrm{g}$ & $\mathrm{AgNO}_{3} / \%$ \\
\hline \multirow{3}{*}{ Ag-SS/PEO nanofiber mats } & 2.1 & 0.9 & 0.5 & 0.5 & 0.1 & 0.005 \\
\hline & 2.1 & 0.9 & 0.5 & 0.5 & 0.1 & 0.01 \\
\hline & 2.1 & 0.9 & 0.5 & 0.5 & 0.1 & 0.02 \\
\hline \multirow{3}{*}{$\mathrm{Ag} / \mathrm{SS} / \mathrm{PEO}$ nanofiber mats } & 2.1 & 0.9 & 0.5 & 0.5 & 0.1 & 0.005 \\
\hline & 2.1 & 0.9 & 0.5 & 0.5 & 0.1 & 0.01 \\
\hline & 2.1 & 0.9 & 0.5 & 0.5 & 0.1 & 0.02 \\
\hline
\end{tabular}

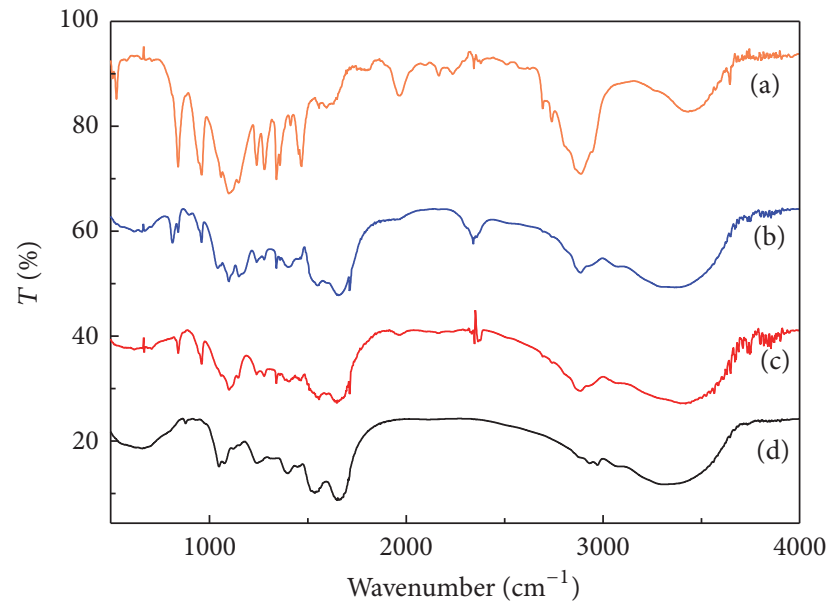

Figure 2: The FT-IR spectra of (a) PEO powders; (b) Ag-SS/PEO nanofiber mats; (c) Ag/SS/PEO nanofiber mats; (d) SS powders.

colonies formed were counted. The inhibitory rate (\%) was determined as follows:

$$
R=\frac{A-B}{A} \times 100 \%,
$$

where $R$ was the percentage of bacterial reduction and $A$ and $B$ were the bacterial colonies before and after being shaken $24 \mathrm{~h}$, respectively.

\section{Results and Discussion}

3.1. FT-IR Spectrum of Nanofiber Mats. Fourier transform infrared spectrometer of the sericin powders, the Ag/SS/PEO nanofiber mats, and the Ag-SS/PEO nanofiber mats (Figure 2) shows that the characteristic absorption bands being appropriate to characterize the structural conformation of sericin are assigned mainly to the peptide bonds in the region named amide I $\left(1600 \sim 1700 \mathrm{~cm}^{-1}\right)$, amide II (1480 $\left.1580 \mathrm{~cm}^{-1}\right)$, and amide III $\left(1220 \sim 1230 \mathrm{~cm}^{-1}\right)$ peaks [15-17].

Figure 3 presents the FT-IR spectra in the range from $600 \mathrm{~cm}^{-1}$ to $1800 \mathrm{~cm}^{-1}$, which reflects comprehensively the primary hydroxyl $(-\mathrm{C}-\mathrm{OH})$ and the primary amino $\left(-\mathrm{C}-\mathrm{NH}_{2}\right)$ groups of sericin. The primary hydroxyl $(-\mathrm{C}-\mathrm{OH})$ of sericin is especially sensitive to the structure of the proteins and this band is broken by the reaction between sericin and silver nitrate solution [18]. The primary amino $\left(-\mathrm{C}-\mathrm{NH}_{2}\right)$ is disturbed by the transmission peak generated of $\mathrm{Ag}^{\circ}$. As a

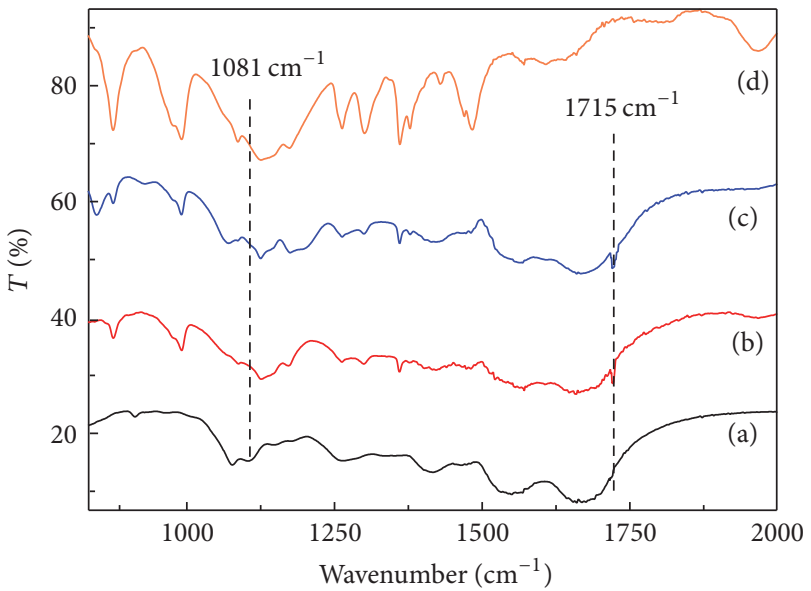

FIgure 3: Spectra $\left(600 \sim 1800 \mathrm{~cm}^{-1}\right)$ of (a) PEO powders; (b) AgSS/PEO nanofiber mats; (c) Ag/SS/PEO nanofiber mats; (d) SS powders.

result, the $-\mathrm{C}-\mathrm{OH}$ and $-\mathrm{C}-\mathrm{NH}_{2}$ band are all appropriate to characterize the structural conformation of sericin in the blend nanofiber mats.

The peak related to the - $\mathrm{C}-\mathrm{OH}$ band stretching vibration at $1081 \mathrm{~cm}^{-1}$ is not shown in the Ag-SS/PEO nanofiber mats and $\mathrm{Ag} / \mathrm{SS} / \mathrm{PEO}$ nanofiber mats, indicating that the primary hydroxyl reacted during the oxidation-reduction reaction between the primary hydroxy of sericin and $\mathrm{Ag}^{+}$of silver nitrate solution. It is shown that the strong absorption peak at $1715 \mathrm{~cm}^{-1}$ appeared in the $\mathrm{Ag}$-SS/PEO nanofiber mats and $\mathrm{Ag} / \mathrm{SS} / \mathrm{PEO}$ nanofiber mats, suggesting that there is small amount of $\mathrm{C}=\mathrm{O}$ stretching vibration which occurred during the oxidation-reduction reaction between sericin and silver nitrate.

3.2. The XRD Spectrum of Nanofiber Mats. XRD was used to examine the crystalline structure and crystallinity of the Ag$\mathrm{SS} / \mathrm{PEO}$ nanofiber mats and $\mathrm{Ag} / \mathrm{SS} / \mathrm{PEO}$ nanofiber mats and the measurements were conducted on them (Figure 4). It can be seen from Figure 4 that there is a new crystalline peak at $38.55^{\circ}$ concerning the nanosilver $(\mathrm{Ag})$ in the $\mathrm{Ag}-\mathrm{SS} / \mathrm{PEO}$ nanofiber mats and Ag/SS/PEO nanofiber mats [19], illustrating that the nanosilver particles are successfully produced by the reaction between $-\mathrm{C}-\mathrm{OH}$ and $\mathrm{Ag}^{+}$. As a result, this is possible for preparing nanosilver loaded nanofiber mats regardless of the precursor and later silver-loaded method [20]. 


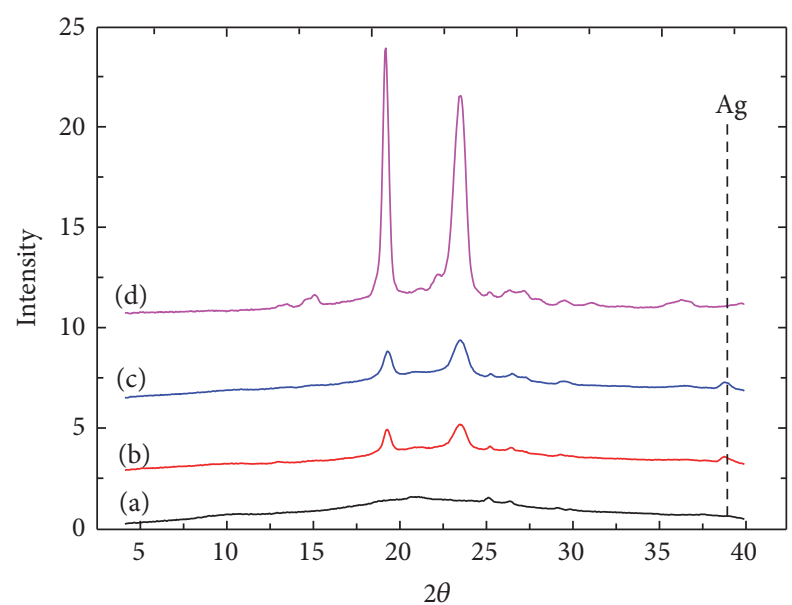

FIgURE 4: The XRD spectra of (a) PEO powders; (b) Ag-SS/PEO nanofiber mats; (c) Ag/SS/PEO nanofiber mats; (d) SS powders.

3.3. Morphology of Nanofiber Mats. The surface microcosmic morphology of the prepared $\mathrm{Ag} / \mathrm{SS} / \mathrm{PEO}$ nanofiber mats and Ag-SS/PEO nanofiber mats was evaluated by SEM (Figures $5(\mathrm{a})$ and $5(\mathrm{~b}))$.

Compared with the surface of Ag-SS/PEO nanofiber mats, the $\mathrm{Ag} / \mathrm{SS} / \mathrm{PEO}$ nanofiber mats possess the rough surface morphologies and have significant nanosilver particles attached to the surface (see Figure 5). It illustrates that the nanosilver particles being prepared by later silver-loaded method are all located on the Ag/SS/PEO nanofiber mats. Also, the larger nanosilver particle is formed by nanosilver accumulated with the increasing content of $\mathrm{Ag}^{\circ}$ [21-23]. However, there are no obvious nanosilver particle on the surface of the Ag-SS/PEO nanofiber mats (Figure 5(b)). This is due to the centripetal force of nanosilver particles during the nanofiber stretching process of electrospinning; the nanosilver particles are almost kept in the Ag-SS/PEO nanofiber mats.

3.4. X-Ray Photoelectron Spectroscopy of Nanofiber Mats. The XPS spectra analysis was applied to confirm the existence of element, based on binding energy of electrons. The XPS spectra analysis on the surface of the $\mathrm{Ag} / \mathrm{SS} / \mathrm{PEO}$ nanofiber mats and Ag-SS/PEO nanofiber mats is conducted to evaluate the structure between the nanofiber mats and nanosilver and the element component of nanofiber mats. The results XPS spectra of the nanofiber mats are shown in Figure 6.

Figure 6 shows that the binding energies of $\mathrm{C} 1 \mathrm{~s}, \mathrm{~N}$ 1s, $\mathrm{O} 1 \mathrm{~s}$, and $\mathrm{Ag} 3 \mathrm{~d}$, respectively, correspond with $285.5 \mathrm{eV}$, $339.1 \mathrm{eV}, 530.6 \mathrm{eV}$, and $368 \mathrm{eV}[24,25]$. There is obvious $\mathrm{Ag} \mathrm{3d}$ peak on the surface of Ag/SS/PEO nanofiber mats at $368 \mathrm{eV}$. However, at this binding energy, there is no $\mathrm{Ag} 3 \mathrm{~d}$ peak on the surface of Ag-SS/PEO nanofiber mats. It indicates that the silver nanoparticles are located on the surface of AgSS/PEO nanofiber mats and the results are kept well with their surface microcosmic morphology of the prepared AgSS/PEO nanofiber mats by SEM test.

The elemental content on the surface of the nanofiber mats is determined based on the XPS spectra analysis in
TABLE 2: The elements content on the surface of nanofiber mats.

\begin{tabular}{lcccc}
\hline \multirow{2}{*}{ Samples } & \multicolumn{4}{c}{ Surface element content/\% } \\
& $\mathrm{C}$ & $\mathrm{N}$ & $\mathrm{O}$ & $\mathrm{Ag}$ \\
\hline Ag-SS/PEO nanofibers & 63.59 & 9.35 & 27.06 & 0 \\
Ag/SS/PEO nanofibers & 63.01 & 8.70 & 28.79 & 0.50 \\
\hline
\end{tabular}

the samples and listed in Table 2. It can be illustrated that the elemental composition of nanofiber mats includes $\mathrm{C}$, $\mathrm{N}, \mathrm{O}$, and Ag. There is no other impurity element detected on the prepared nanofiber mats, which illustrates that the nanofiber mats have high purity and might be suitable for the application in medical dressing.

The Ag $3 \mathrm{~d}_{5 / 2,3 / 2}$ spectra from the Ag/SS/PEO nanofiber mats are resolved in Gaussian-shaped bands shown in Figure 7. The two distinct features with peak positions located at 284.7 and $287.9 \mathrm{eV}$ are separately associated with the binding energy of $\mathrm{Ag} 3 \mathrm{~d}_{5 / 2}$ and $\mathrm{Ag} 3 \mathrm{~d}_{3 / 2}$ [26]. This fully illustrates the existence of silver on the surface of $\mathrm{Ag} / \mathrm{SS} / \mathrm{PEO}$ nanofiber mats. In addition, the peak width of $\mathrm{Ag} 3 \mathrm{~d}_{5 / 2}$ and $\mathrm{Ag} 3 \mathrm{~d}_{3 / 2}$ is similar and the maximum binding energy differences between the $\mathrm{Ag} 3 \mathrm{~d}_{5 / 2}$ and $\mathrm{Ag} 3 \mathrm{~d}_{3 / 2}$ are lowered $6 \mathrm{eV}$.

\subsection{In Situ Fabrication and Characterization of Silver Nano-} particles. Nanosilver was synthesized through a clean synthesis procedure using the sericin as reducing agent. The specific interactions between sericin and silver nitrate are shown in Figure 8.

The functional groups such as hydroxyl groups, amino groups, and carboxy group of sericin all have electron donor groups capable to reduce $\mathrm{Ag}^{+}$to $\mathrm{Ag}^{\circ}$ [27-29]. The nucleation of nanosilver particle is formed and grown by accumulating with $\mathrm{Ag}^{\circ}$. The nanosilver particle is finally obtained by reaching the balance between the $\mathrm{Ag}^{\circ}$ content of nucleation surface and the reduction solutions. The nanoparticle size analyzer was used to the Ag-SS solution to test the nanosilver particle size at silver content of $0.005 \%, 0.01 \%$, and $0.02 \%$, separately. The nanosilver particle size distribution by number in the AgSS solution is shown in Figure 9.

It is shown that the nanosilver particle with different concentration silver nitrate ethanol solution is formed with the different diameters size. The nanosilver diameter in AgSS solution with the silver content at $0.005 \%$ has a major distribution of $1 \sim 10 \mathrm{~nm}$. Increasing the silver content from $0.01 \%$ to $0.02 \%$, the size distribution of silver particle reaches from $20 \mathrm{~nm}$ to $60 \mathrm{~nm}$, respectively (Figure 9). This can be due to the increases of silver nitrate concentration, and the balance between the $\mathrm{Ag}^{\circ}$ content of nucleation surface and the reduction sericin solutions is hardly reached, resulting in the larger nanosilver particle size [30]. In conclusion, the size diameters of the different nanosilver contents are all about below $100 \mathrm{~nm}$.

3.6. Antimicrobial Activity of Nanofiber Mats. The antibacterial efficiency of Ag/SS/PEO nanofiber mats and Ag-SS/PEO nanofiber mats evaluated after the specific contact time and calculated by reduction percent of $E$. coli and $S$. aureus was 


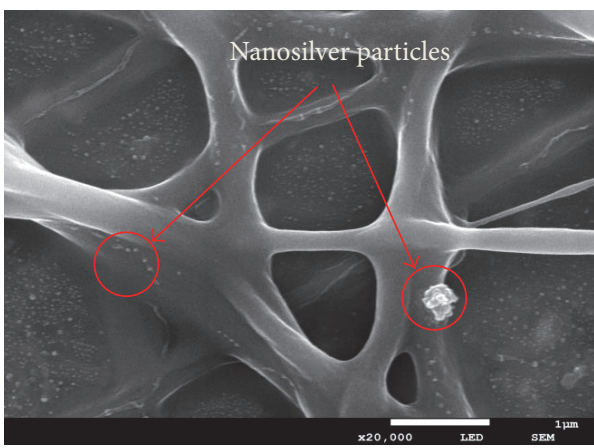

(a)

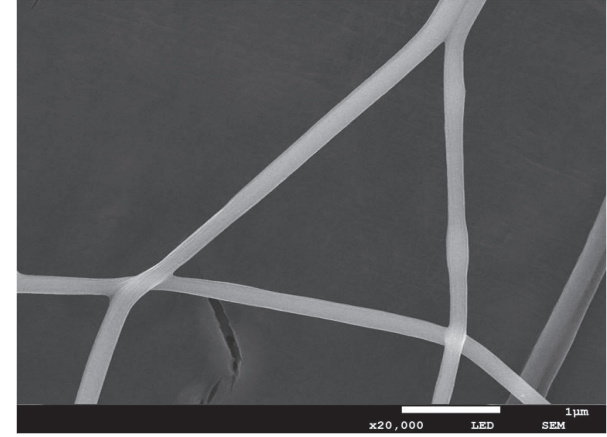

(b)

FIgURE 5: The morphology of nanofibers. (a) Ag/SS/PEO nanofibers; (b) Ag-SS/PEO nanofiber mats.

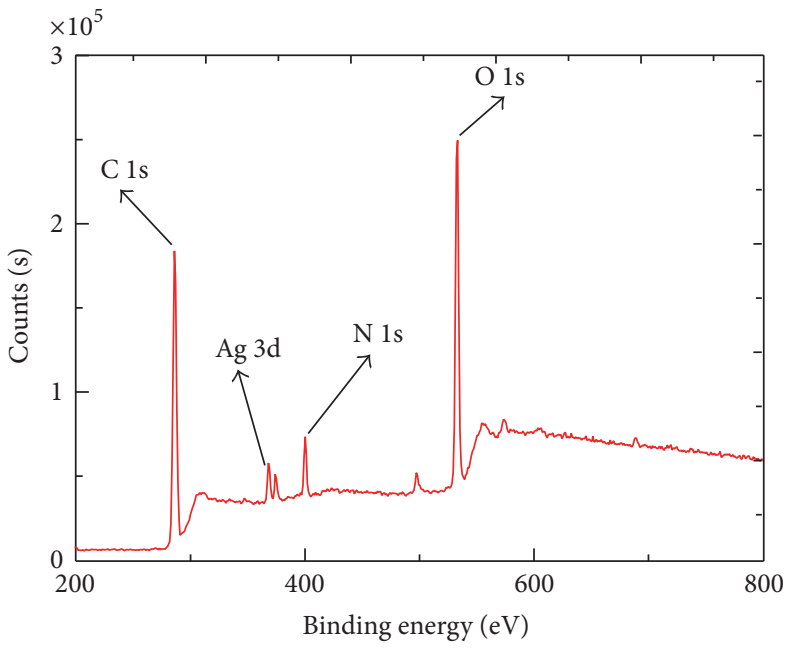

(a)

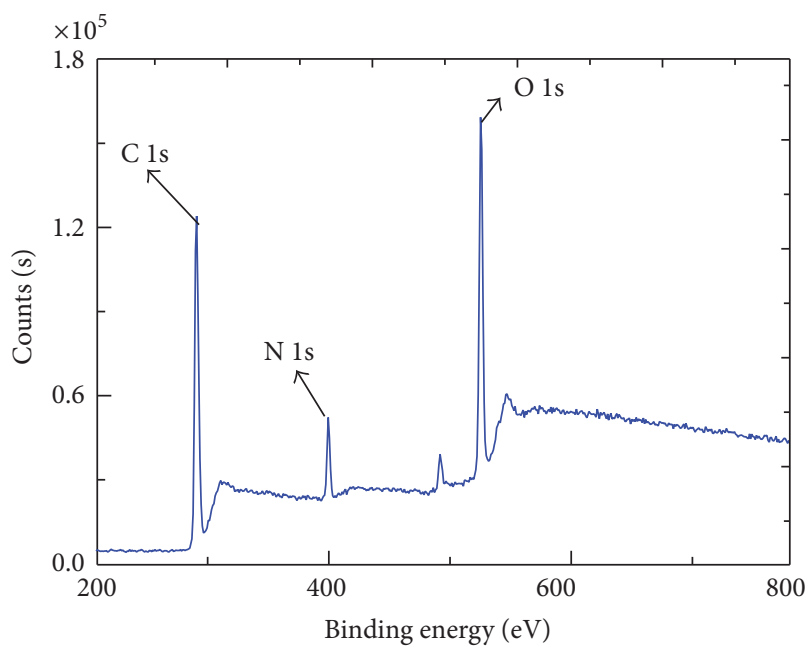

(b)

FIGURE 6: The XPS spectra of nanofiber mats. (a) Ag/SS/PEO nanofiber mats; (b) Ag-SS/PEO nanofiber mats.

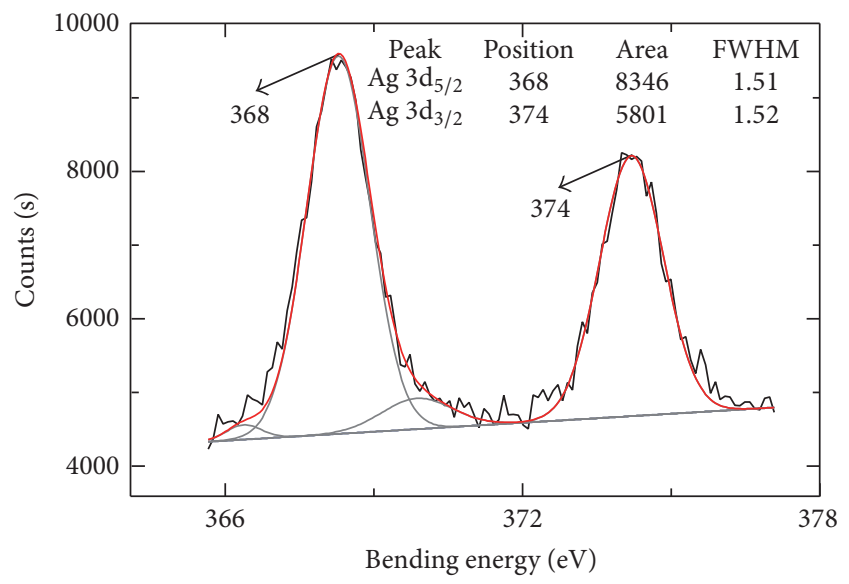

Figure 7: The $\mathrm{Ag} 3 \mathrm{~d}_{5 / 2,3 / 2}$ spectra from the Ag/SS/PEO nanofiber mats.

shown in Table 3. It is found that with the increasing of the silver content for nanofiber mats, the bacterial reduction rates of samples against $S$. aureus and E. coli are increased gradually. When the silver content is about $0.005 \%$, the bacterial reduction rates of the Ag/SS/PEO nanofiber mats $S$. aureus and E. coli have, respectively, reached 90.93 and 89.92\%. However, at this same silver content, the bacterial reduction rates of $\mathrm{Ag}-\mathrm{SS} / \mathrm{PEO}$ nanofiber mats against $S$. aureus and E. coli only reach $65.03 \%$ and $50.79 \%$. As a result, the later silver-loaded method improves materials antimicrobial property compared with the normal methods $[31,32]$ and makes the bacterial reduction rates of nanofiber mats against $S$. aureus and E. coli reach about $99.99 \%$ with the silver content at $0.02 \%$. The antimicrobial activity of nanofiber mats is increased greatly and this may be due to reducing the moving friction of nanosilvers and resulting in the improving of nanosilvers particles effective utilization.

\section{Conclusions}

Our findings show that the deposition method of nanosilver is critical for the antibacterial property of nanofiber mats. Electrospinning-combined postdeposition method is able to fabricate the super-antibacterial $\mathrm{Ag} / \mathrm{SS} / \mathrm{PEO}$ nanofiber 


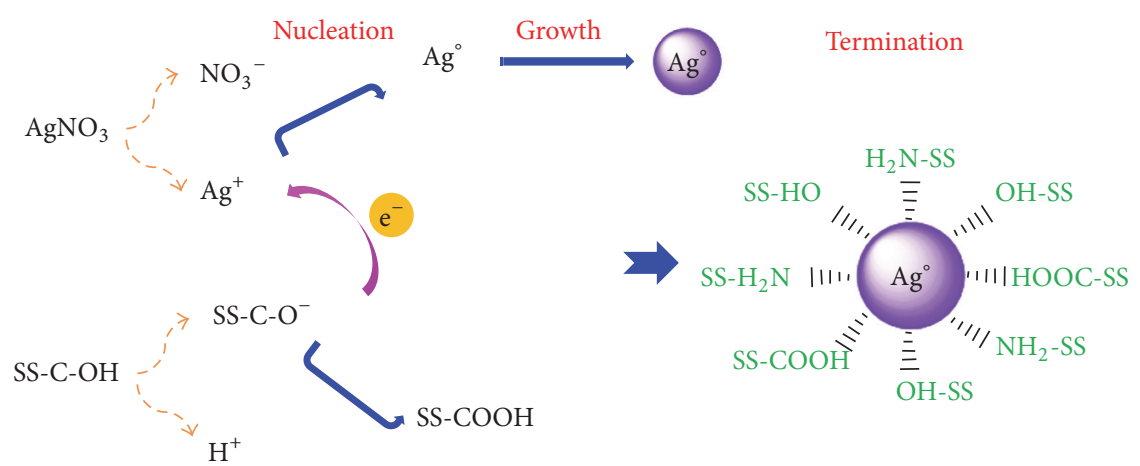

FIGURE 8: The mechanism reaction of synthesis of $\mathrm{AgNO}_{3}$ with SS.

TABle 3: Antibacterial activities of the nanofiber mats.

\begin{tabular}{|c|c|c|c|c|c|}
\hline & \multirow{2}{*}{ Silver nitrate content (\%) } & \multicolumn{2}{|c|}{ E. coli } & \multicolumn{2}{|l|}{ S. aureus } \\
\hline & & Surviving cells $(\mathrm{CFU} / \mathrm{mL})$ & Reduction (\%) & Surviving cells $(\mathrm{CFU} / \mathrm{mL})$ & Reduction (\%) \\
\hline \multirow{3}{*}{ Ag-SS/PEO nanofiber mats } & 0.005 & $8.04 \times 10^{5}$ & 65.03 & $0.50 \times 10^{5}$ & 50.79 \\
\hline & 0.01 & $4.24 \times 10^{5}$ & 70.11 & $1.12 \times 10^{5}$ & 61.45 \\
\hline & 0.02 & $2.24 \times 10^{5}$ & 85.25 & $5.20 \times 10^{4}$ & 80.97 \\
\hline \multirow{3}{*}{$\mathrm{Ag} / \mathrm{SS} / \mathrm{PEO}$ nanofiber mats } & 0.005 & $1.04 \times 10^{4}$ & 90.93 & $1.20 \times 10^{4}$ & 89.92 \\
\hline & 0.01 & $4.04 \times 10^{3}$ & 95.97 & $1.20 \times 10^{3}$ & 95.96 \\
\hline & 0.02 & $<30$ & 99.99 & $<30$ & 99.99 \\
\hline
\end{tabular}

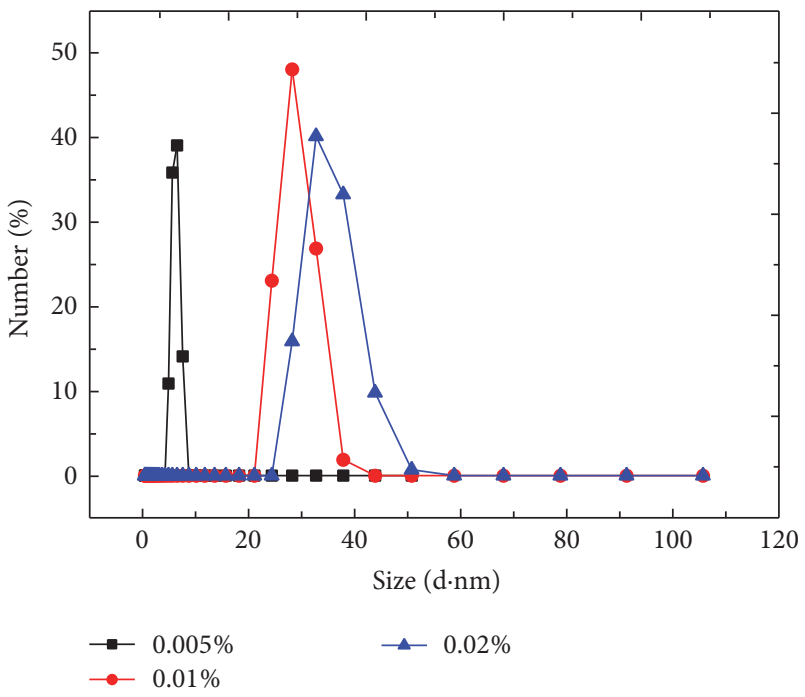

Figure 9: Particle size distribution of number for nanosilver particle.

mats at the lower silver content and enhance the nanosilver utilization. The Ag/SS/PEO nanofiber mats have shown the extremely strong antibacterial properties and the bacterial reduction rates against $S$. aureus and $E$. coli are all above $99.99 \%$ with the silver content at $0.02 \%$. The bacterial reduction rates of Ag-SS/PEO nanofiber mats by the general method against S. aureus and E. coli only are $85.25 \%$ and $80.97 \%$ at the same silver content. This illustrates that the nanosilver particles effective utilization is improved when being attached to the outside of nanofiber mats by later silver-loaded method. The resulting nanosilver particle has a narrow particle size distribution, with average particle size of approximately $20 \mathrm{~nm}$ and the smallest nanosilver particle size is about $5 \mathrm{~nm}$. The $\mathrm{X}$-ray photoelectron spectroscopy also clearly reveals that there is obvious $\mathrm{Ag} 3 \mathrm{~d}$ peak on the surface of $\mathrm{Ag} / \mathrm{SS} / \mathrm{PEO}$ nanofiber mats at $368 \mathrm{eV}$. At this binding energy, there is no Ag $3 \mathrm{~d}$ peak on the surface of Ag-SS/PEO nanofiber mats. This indicates that the silver nanoparticles are almost located outside the surface of $\mathrm{Ag} / \mathrm{SS} / \mathrm{PEO}$ nanofiber mats.

\section{Competing Interests}

The authors declare that there are no competing interests.

\section{Authors' Contributions}

Jia Li and Bo-Xiang Wang contributed equally to this work.

\section{Acknowledgments}

This work was supported by Programs of the Natural Science Foundation of China (no. 51343002), Natural Science Foundation of Liaoning Province (no. 201602341), Liaoning Provincial Key Laboratory of Functional Textile Materials, Liaoning BaiQianWan Talents Program, The Youth Fund Project of Eastern Liaoning University (2015QN004; 2015QN003), and Education Department Funds of Liaoning Province (no. L2015188) Liaoning Excellent Talents in University and Key Program of Eastern Liaoning University (2015JC002, 2015GG003, and 2015GG004). 


\section{References}

[1] B. B. Mandal, A. S. Priya, and S. C. Kundu, "Novel silk sericin/gelatin 3-D scaffolds and 2-D films: fabrication and characterization for potential tissue engineering applications," Acta Biomaterialia, vol. 5, no. 8, pp. 3007-3020, 2009.

[2] S. H. Oh, S. G. Kang, E. S. Kim, S. H. Cho, and J. H. Lee, "Fabrication and characterization of hydrophilic poly(lactic-coglycolic acid)/poly(vinyl alcohol) blend cell scaffolds by meltmolding particulate-leaching method," Biomaterials, vol. 24, no. 22, pp. 4011-4021, 2003.

[3] M. Montazer and S. B. Malekzadeh, "Electrospun antibacterial nylon nanofibers through in situ synthesis of nanosilver: preparation and characteristics," Journal of Polymer Research, vol. 19, no. 10, article 9980, pp. 1-6, 2012.

[4] L. Guo, B. Duan, and L. Zhang, "Construction of controllable size silver nanoparticles immobilized on nanofibers of chitin microspheres via green pathway," Nano Research, vol. 9, no. 7, pp. 2149-2161, 2016.

[5] X. Zhuang, Z. Li, W. Kang, and B. Cheng, "Electrospun antibacterial chitosan/poly (vinyl alcohol) nanofibers containing silver nanoparticles," Advanced Materials Research, vol. 152-153, pp. 1333-1336, 2011.

[6] D. Sun, J. Yang, J. Yu, and X. Yang, "Preparation of novel $\mathrm{Ag} /$ bacterial cellulose hybrid nanofibers for antimicrobial wound dressing," Advanced Materials Research, vol. 152-153, pp. 1771-1774, 2011.

[7] Y. Hang, Y. Zhang, Y. Jin, H. Shao, and X. Hu, "Preparation of regenerated silk fibroin/silk sericin fibers by coaxial electrospinning," International Journal of Biological Macromolecules, vol. 51, no. 5, pp. 980-986, 2012.

[8] B. C. Dash, B. B. Mandal, and S. C. Kundu, "Silk gland sericin protein membranes: fabrication and characterization for potential biotechnological applications," Journal of Biotechnology, vol. 144, no. 4, pp. 321-329, 2009.

[9] E. Hadipour-Goudarzi, M. Montazer, M. Latifi, and A. A. G. Aghaji, "Electrospinning of chitosan/sericin/PVA nanofibers incorporated with in situ synthesis of nano silver," Carbohydrate Polymers, vol. 113, no. 1-3, pp. 231-239, 2014.

[10] R. F. Hamilton Jr., S. Buckingham, and A. Holian, "The effect of size on Ag nanosphere toxicity in macrophage cell models and lung epithelial cell lines is dependent on particle dissolution," International Journal of Molecular Sciences, vol. 15, no. 4, pp. 6815-6830, 2014.

[11] Y. Liu, X. Yu, J. Li et al., "Fabrication and properties of highcontent keratin/poly (ethylene oxide) blend nanofibers using two-step cross-linking process," Journal of Nanomaterials, vol. 2015, Article ID 803937, 7 pages, 2015.

[12] M. Pakravan, M.-C. Heuzey, and A. Ajji, "A fundamental study of chitosan/PEO electrospinning," Polymer, vol. 52, no. 21, pp. 4813-4824, 2011.

[13] I. Rashkov, "Preparation of chitosan-containing nanofibres by electrospinning of chitosan/poly(ethylene oxide) blend solutions," e-Polymers, vol. 4, no. 1, pp. 624-635, 2004.

[14] A. Aluigi, A. Varesano, A. Montarsolo et al., "Electrospinning of keratin/poly(ethylene oxide) blend nanofibers," Journal of Applied Polymer Science, vol. 104, no. 2, pp. 863-870, 2007.

[15] P. Srihanam, W. Simcheur, and Y. Srisuwan, "Study on silk sericin and chitosan blend film: morphology and secondary structure characterizations," Pakistan Journal of Biological Sciences, vol. 12, no. 22, pp. 1487-1490, 2009.
[16] H. Teramoto and M. Miyazawa, "Molecular orientation behavior of silk sericin film as revealed by ATR infrared spectroscopy," Biomacromolecules, vol. 6, no. 4, pp. 2049-2057, 2005.

[17] X. M. Zhang and P. Wyeth, "Using FTIR spectroscopy to detect sericin on historic silk," Science China Chemistry, vol. 53, no. 3, pp. 626-631, 2010.

[18] M. Cakić, S. Glišić, G. Nikolić, G. M. Nikolić, K. Cakić, and M. Cvetinov, "Synthesis, characterization and antimicrobial activity of dextran sulphate stabilized silver nanoparticles," Journal of Molecular Structure, vol. 1110, pp. 156-161, 2016.

[19] A. Adamczyk and M. Rokita, "The structural studies of Ag containing $\mathrm{TiO}_{2}-\mathrm{SiO}_{2}$ gels and thin films deposited on steel," Journal of Molecular Structure, vol. 1114, pp. 171-180, 2016.

[20] Y. N. Jo and I. C. Um, "Effects of solvent on the solution properties, structural characteristics and properties of silk sericin," International Journal of Biological Macromolecules, vol. 78, pp. 287-295, 2015.

[21] S. Anita, T. Ramachandran, R. Rajendran, C. Koushik, and M. Mahalakshmi, "A study of the antimicrobial property of encapsulated copper oxide nanoparticles on cotton fabric," Textile Research Journal, vol. 81, no. 10, pp. 1081-1088, 2011.

[22] A. D. Erem, G. Ozcan, H. H. Erem, and M. Skrifvars, "Antimicrobial activity of poly(L-lactide acid)/silver nanocomposite fibers," Textile Research Journal, vol. 83, no. 20, pp. 2111-2117, 2013.

[23] H. J. Lee and S. H. Jeong, "Bacteriostasis and skin innoxiousness of nanosize silver colloids on textile fabrics," Textile Research Journal, vol. 75, no. 7, pp. 551-556, 2005.

[24] H. Piao, M. C. N. Enever, K. Adib, J. Hrbek, and M. A. Barteau, "High resolution X-ray photoelectron spectroscopy of styrene oxide adsorption and reaction on $\operatorname{Ag}(111)$," Surface Science, vol. 571, no. 1-3, pp. 139-145, 2004.

[25] D. N. Wijesundera, I. Rajapaksa, X. Wang, J.-R. Liu, I. Rusakova, and W.-K. Chu, "Ion beam engineered nano silver silicon substrates for surface enhanced Raman spectroscopy," Journal of Raman Spectroscopy, vol. 44, no. 7, pp. 1014-1017, 2013.

[26] R. K. Debnath, A. G. Fitzgerald, and K. Christova, "X-ray photoelectron spectroscopy studies of Ag-doped thin amorphous $\mathrm{Ge}_{x} \mathrm{Sb}_{40-x} \mathrm{~S}_{60}$ films," Applied Surface Science, vol. 202, no. 3-4, pp. 261-265, 2002.

[27] J. A. Kiernan, "Formaldehyde, formalin, paraformaldehyde and glutaraldehyde: what they are and what they do," Microscopy Today, vol. 8, no. 1, pp. 8-12, 2000.

[28] T. Daba, K. Kojima, and K. Inouye, "Chemical modification of wheat $\beta$-amylase by trinitrobenzenesulfonic acid, methoxypolyethylene glycol, and glutaraldehyde to improve its thermal stability and activity," Enzyme \& Microbial Technology, vol. 53, no. 6-7, pp. 420-426, 2013.

[29] P. Aramwit, T. Siritientong, S. Kanokpanont, and T. Srichana, "Formulation and characterization of silk sericin-PVA scaffold crosslinked with genipin," International Journal of Biological Macromolecules, vol. 47, no. 5, pp. 668-675, 2010.

[30] S. Terada, M. Sasaki, K. Yanagihara, and H. Yamada, "Preparation of silk protein sericin as mitogenic factor for better mammalian cell culture," Journal of Bioscience \& Bioengineering, vol. 100, no. 6, pp. 667-671, 2005.

[31] A. Pan, "Preparation of Ag/HBP/PAN nanofiber web and its antimicrobial and filtration property," Journal of Nanomaterials, vol. 2016, Article ID 4515769, 10 pages, 2016.

[32] F. Zhang, Y. Tao, S. Chen, and Y. Lu, "Preparation and properties of the silver loaded activated carbon fibers," Fibers \& Polymers, vol. 16, no. 9, pp. 2003-2010, 2015. 

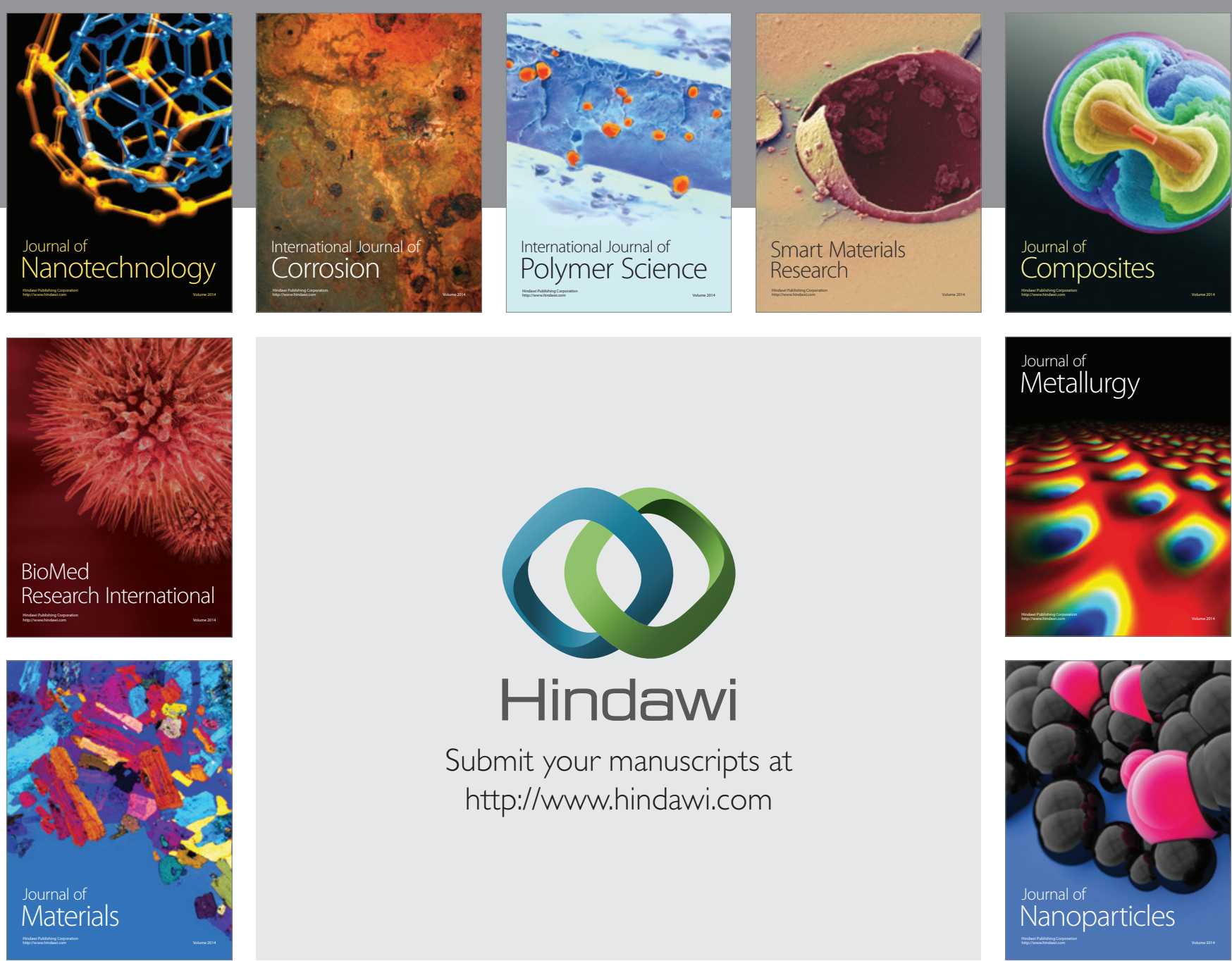

\section{Hindawi}

Submit your manuscripts at

http://www.hindawi.com

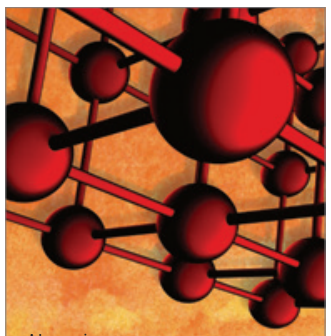

Materials Science and Engineering
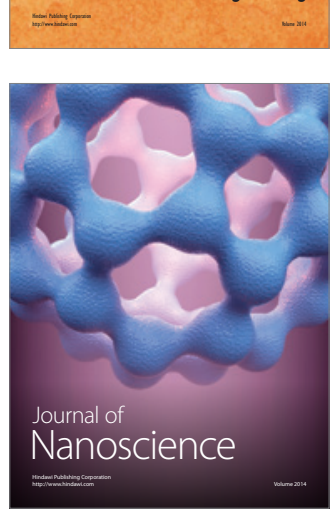
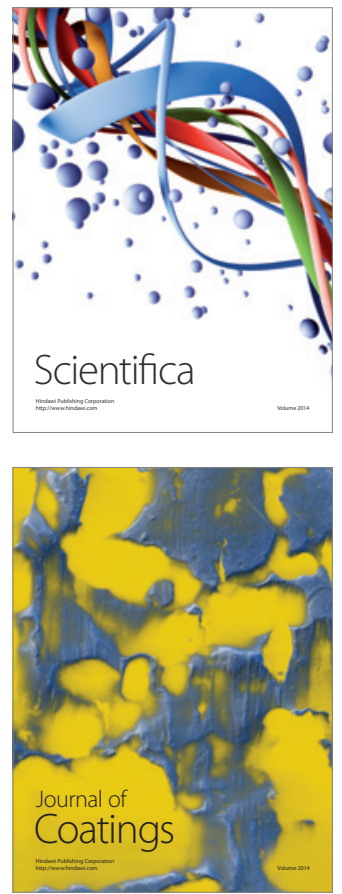
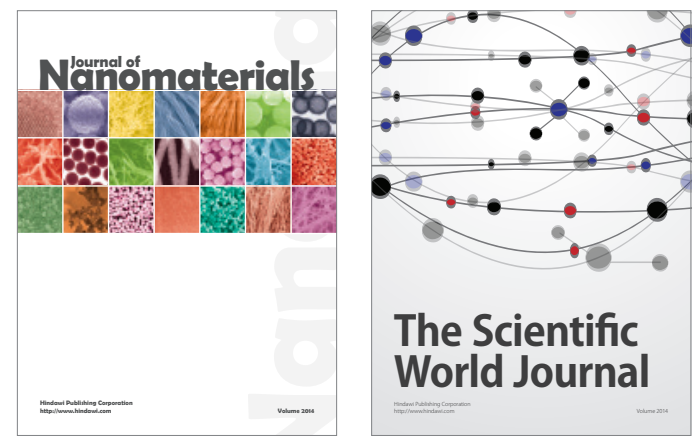

The Scientific World Journal
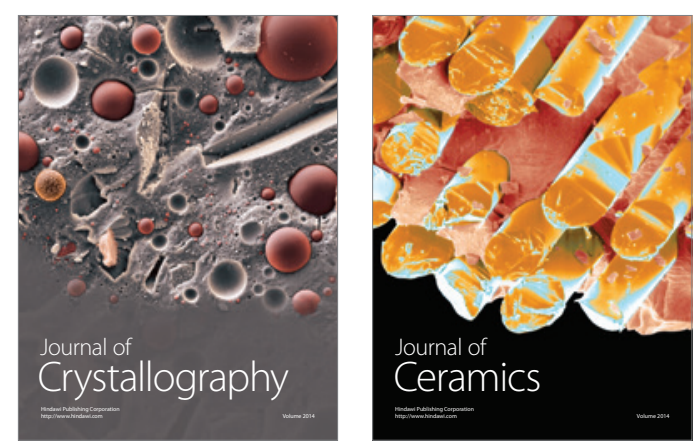
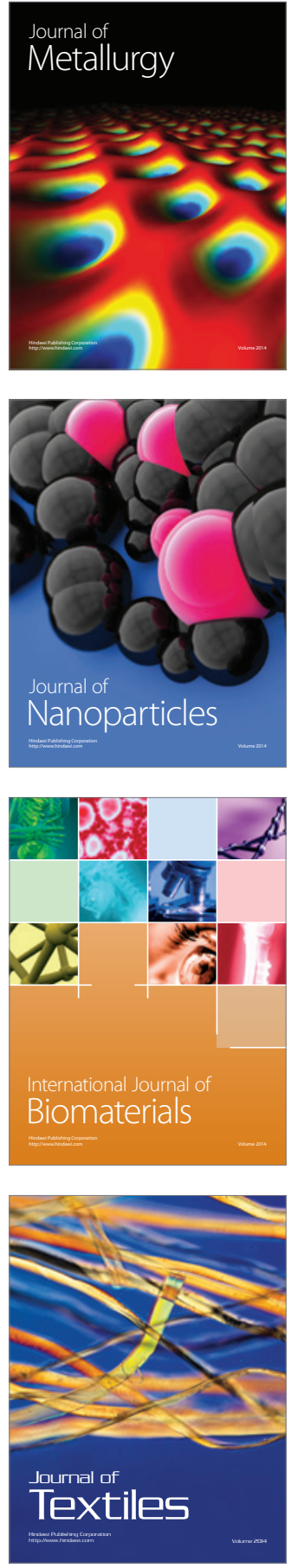